\title{
Analisa Pembayaran Perkuliahan Dengan Virtual Account Pada Universitas Raharja
}

\author{
Padeli $^{1}$, Eduard Hotman Purba ${ }^{2}$, Bonari Simanjuntak ${ }^{* 3}$ \\ ${ }^{1}$ Program Studi Komputerisasi Akuntansi Fakultas Sains dan Teknologi Universitas Raharja, \\ ${ }^{2,}$ Program Studi Sistem Informasi Fakultas Sains dan Teknologi Universitas Raharja \\ E-mail : ${ }^{1}$ padeli@ raharja.info, ${ }^{2}$ eduard@ raharja.info, ${ }^{* 3}$ bonari@ raharja.info
}

\begin{abstract}
Abstrak
Dalam dunia akademik, setiap institusi pendidikan pastinya mempunyai sistem pembayaran perkuliahan, dan dengan kemajuaan teknologi yang pesat sekarang ini, institusi pendidikan dituntut membuat sistem yang efektif dan efisien dan relevan dengan teknologi saat ini yang mana akan membuatnya unggul dalam persaingan dalam lingkup instansi terkait. di Universitas Raharja pembayaran perkuliahan masih menggunakan sistem konvensional di mana mahasiswa transfer dan staff kampus melakukan pengecekan yang mana dinilai kurang efisien. Dalam penelitian ini penulis menggunakan analisa SWOT antara sistem pembayaran virtual account dengan sistem berjalan. Tujuan penelitian ini untuk merekomendasikan penggunaan Virtual Account pada pembayaran perkuliahan di Universitas Raharja Penelitian ini diharapkan menjadi Alternatif pemecahan masalah yang memudahkan mahasiswa dalam melakukan pembayaran keuangan, juga memudahkan kampus dalam memonitoring pembayaran kampus
\end{abstract}

Kata Kunci-Sistem Pembayaran Perkuliahan, Virtual Account, Institusi Pendidikan

\begin{abstract}
In the academic world, every educational institution must have a tuition payment system, and with the rapid technological advances nowadays, educational institutions are required to create systems that are effective and efficient and relevant to current technology which will make it superior in competition within the scope of relevant agencies. At Raharja University, lecture payments still use a conventional system where transfer students and campus staff check which is considered less efficient. In this study, the writer uses a SWOT analysis between the virtual account payment system and the running system. The purpose of this study is to recommend the use of a Virtual Account in the payment of lectures at Raharja University. This research is expected to be a problem solving alternative that makes it easier for students to make financial payments, as well as facilitate campus monitoring of campus payments.
\end{abstract}

Keywords - Lecture Payment Systems, Virtual Accounts, Educational Institutions 


\section{PENDAHULUAN}

Seiring tumbuh dan berkembangnya teknologi Perguruan Tinggi Raharja ingin meningkatkan kualitas dan mendorong bagian keuangan untuk berusaha mengatasi segala permasalahan yang ada sehingga menuntut kemampuan dan kecakapan di bagian keuangan dalam memberikan pelayanan terbaik kepada mahasiswa.Dan metode pembayaran yang relevan pada saat ini adalah Virtual Account yang mempunyai kelebihan praktis, simple tanpa harus melakukan konfirmasi pembayaran, dan dapat dipakai kapanpun dan dimanapun.

Universitas Raharja yang termasuk pada universitas swasta yang memiliki kebijakan tersendiri dalam hal pengelolaan dana operasional perkuliahan mengacu pada peraturan universitas, dimana pembayaran perkuliahan dilakukan sebelum semester baru dimulai dan saat mahasiswa telah selesai mengisi KRS (Kartu Rencana Studi) pada sistem informasi mahasiswa. Pembayaran perkuliahan yang digunakan pada Universitas Raharja adalah menggunakan pembayaran manual yang mana para mahasiswa diharuskan melakukan transfer kepada rekening yayasan/Universitas, namun kampus telah menyediakan mesin atm di dalam kasir jadi mahasiswa dapat melakukan pembayaran di kasir, berikut gambaran proses pembayaran.

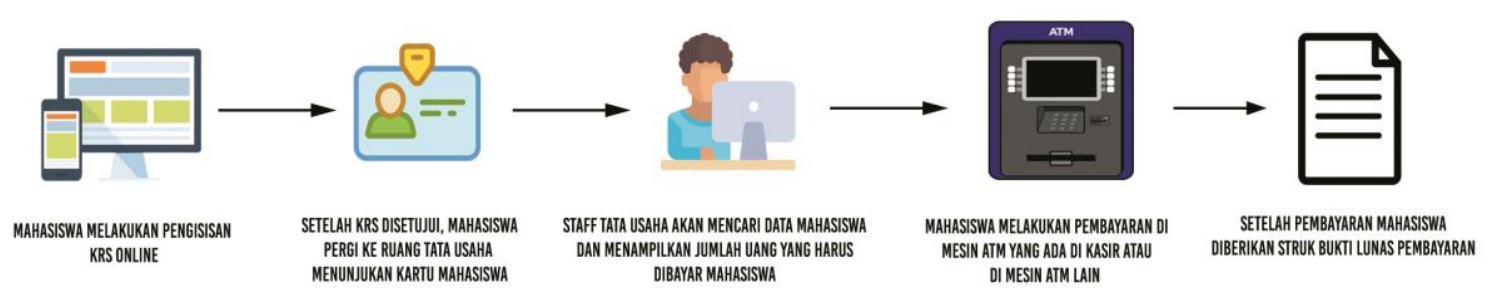

Gambar 1. Alur Pembayaran Perkuliahaan Saat ini

Gambar diatas adalah alur sistem transfer bank manual dan juga pembayaran tunai dengan menggunakan nomor rekening yayasan. terdapat beberapa kendala dan kekurangan sehingga masih belum efektif. Oleh karena itu pembayaran sangat berperan penting dalam kualitas pelayanan kampus terutama untuk pelayanan keuangan untuk mahasiswa.

Berdasarkan gambar diatas terdapat beberapa kendala yang dapat terjadi, antara lain:

a. Transfer menggunakan nomor rekening masih menyulitkan mahasiswa karena sering terjadi kesalahan penulisan nomor rekening yayasan dan sulitnya mahasiswa dalam menghafal nomor rekening yayasan sehingga jika mahasiswa tidak menyimpan nomor rekening harus meminta ke bagian kasir terlebih dahulu jika ingin melakukan pembayaran sehingga membuang-buang waktu.

b. Dan juga bagian staff yang harus menyingkronkan manual data calon mahasiswa yang sudah membayar.

Proses yang berjalan saat ini telah berjalan cukup baik. Namun efisiensi waktu dan kemudahan dalam menyelesaikan proses tersebut lah yang ingin diteliti oleh penulis sehingga dengan dilakukannya penelitian ini diharapkan ditemukan solusi untuk mengatasi permasalahan tersebut. 


\section{METODE PENELITIAN}

Kemudian demi menunjang penelitian ini, maka menggunakan sebuah metode penelitian untuk mencapai tujuan dan mendapatkan informasi yang akurat dan terpercaya dengan metode penelitian studi pustaka yang menghimpunkan beberapa jurnal yang relevan dengan sistem yang sedang dibahas pada penelitian ini. Peneliti melakukan beberapa tahapan dalam penelitian.

\subsection{Metode studi pustaka}

Banyak penelitian-penelitian yang sebelumnya sudah dilakukan mengenai pengolahan sistem pembayaran dengan virtual account. Dalam upaya perlu dilakukannya studi pustaka sebagai salah satu dari penerapan metode penelitian yang akan dilakukan yaitu dengan mengidentifikasikan kesenjangan (identify gaps), menghindari pembuatan ulang (reinventing the wheel), mengidentifikasikan metode yang pernah dilakukan, serta mengetahui penelitian lain yang spesialisasi dan area penelitian yang sama dibidang ini. Berikut adalah 6 (enam) penelitian yang telah dilakukan dan memiliki kolerasi searah dengan penelitian yang akan dibahas dalam penelitian ini, antara lain:

1. Penelitian ini dilakukan oleh Untung Raharja, dkk (2017) yang berjudul "Penerapan menu konfirmasi pembayaran online berbasis Yii pada perguruan tinggi". Yang menyebutkan sistem pembayaran saat ini sudah menggunakan sistem berbasis modernisasi atau online, yang sangat dibutuhkan pada era globalisaasi ini, dan bagaimana peranan transaksi online menjadi sangat penting bagi masyarakat modern.

2. This research conducted by Zlatko Bezhovski (2016) entitled "The Future of the Mobile Payment as Electronic Payment System". The development of the Internet and the arrival of e-commerce fostered digitalization in the payment processes by providing a variety of electronic payment options including payment cards (credit and debit), digital and mobile wallets, electronic cash, contactless payment methods etc. Mobile payment services with their increasing popularity are presently under the phase of transition, heading towards a promising future of tentative possibilities along with the innovation in technology.

3. Penelitian ini dilakukan oleh Erikson Damanik,(2012), dengan judul "Perancangan sistem informasi pembayaran online menggunakan Payment Gateway". Transaksi elektronik menguntungkan karena dapat mengurangi biaya transaksi bisnis dan dapat memperbaiki kualitas pelayanan kepada pelanggan.Walaupun demikian, sering sekali layanan yang ditawarkan melalui media elektronik mudah sekali disalahgunakan oleh pihak - pihak yang tidak bertanggung jawab. Seperti halnya pada saat terjadi komunikasi yang melibatkan jumlah potongan yang harus dilakukan oleh akun bank tertentu dan penambahan nilai uang pada akun yang lain.

4. Penelitian ini dilakukan oleh Dwiki Fahliandhini (2016) dengan judul penelitian "Penerapan Virtual Account sebagai media pembayaran perkuliahan pada perguruan tinggi". yang menjelaskan bahwa dengan menggunakan Virtual Acount akan memudahkan mahasiswa dan juga kampus. Dan kelebihan virtual account dalam pengidentifikasian personal

5. This research conducted byMohammad Auwal Kabil,Siti Zabaedah Zaidin and Aidi Ahmi (2015) entitled "Adoption of e-payment system: a riview of literature". E-payment system is increasingly becoming a daring means of payments in today's business world. This is due to its efficiency, convenience and timeliness. It is a payment system that is continuously being embraced and adopted in the financial system of both developed and developing countries with a view to simplify and ease payments in business transactions. As a result, many studies were conducted around the globe by scholars on epayment adoption. It is based on this that this research paper looks at the available past literature on e-payment adoption across the world, with a view to highlight the scope, methodology and Information System (IS) models used by previous researchers so as to identify research gaps and recommend such for future studies. The study employed an extensive literature search on e-payment 
adoption with the aid of Google Scholar for those recent studies between the years 20102015. To facilitate the understanding of the issue under study, previous studies were analysed based on scope-geographical location of the study, theories/models adopted and methodology used. Finally, the paper has identified the patterns of previous researches with regards to these three items and further highlights and recommends key areas in which future research should delve on

6. This research was conducted by Ajeet Singh, Karan Singh, Sahazad, M.H Khan, Manik Chandra (2012)entitled “A Review: Secure Payment System for Electronic Transaction".In this paper we review a secure electronic payment system for Internet transaction. The electronic payment system is to be secure for Internet transaction participants such as Payment gateway server, Bank sever and Merchant server. The security architecture of the system is designed by using Many Security Protocols and techniques, which eliminates the fraud that occurs today with stolen credit card/debit card payment information and customer information. Electronic commerce involves the exchange of some form of money for goods and services over the Internet but today, Internet is an insecure and unreliable media. The asymmetric key cryptosystem Methodology with help of Security Protocol, secure communication tunnel techniques can protect conventional transaction data such as account numbers, amount and other information. Requiring a basic familiarity with computing and networking, the book covers various Internet payment systems including Ecash

7. This research was conducted by Stephen Kwadwo Antwi,Kasim Hamzah,Shadrach Wusah Bavoh (2015) Study entitled "Electronic Examining the Effectiveness of Electronic Payment System in Ghana: The Case of e-ZWICH in the Tamale Metropolis". The purpose of this paper is There have been significant development of technological innovations in Ghana's banking sector and financial services in general. The introduction of e-ZWICH in Ghana in 2008 came with so much euphoria as great news meant to move the country towards a cashless economy. Many Ghanaians signed on to the first biometric payment system - the eZWICH. After several years, the interest and patronage seem to have waned drastically. The study examines the effectiveness of that form of electronic payment system in the Tamale metropolis in Ghana. The study adopts questionnaire administration to ascertain the common types of e-payment systems, the level of adoption of e-ZWICH, and the factors affecting its effectiveness. This study reveals that there is low patronage of the e-ZWICH smart card due to frequent link failures, long queues in banking halls and limited point-ofsale devices. This has stalled the effective adoption and use of the system. The study recommends that the innovators and regulators introduce measures to renew the interest of stakeholders through sensitization workshops, making the point-of-sale devices more available and enhancing the smooth operation of the devices.

8. This research conducted by Saviour F (2018) entitled "A Study on Popularity of Various Utilities of E-Payment Mechanism among Students". An E-payment system is a way of making transactions or paying for goods and services through an electronic medium. The electronic payment system has grown tremendously over the last few decades due to the widely spread use of internet-based banking services. As the world advances more with technology development, we can see the rise of E-payment systems and payment processing devices. The present paper throws light upon the popularity of various utilities of e-payment Mechanism among students. It focuses on the utilities of E-payment Mechanism.

\subsection{Metode Observasi (Pengamatan Langsung)}

Metode ini merupakan sebuah pengamatan pada sistem yang sedang berjalan dan sistem yang berkaitan dengan penelitian yang sedang dilakukan. Sehingga data yang terkumpul dapat digunakan sebagai informasi lebih lanjut mengenai pembayaran perkuliahan dengan virtual account sehingga dapat memudahkan mahasiswa dalam melakukan pembayaran perkuliahan di Universitas Raharja 


\subsection{Implementasi}

Pada penelitian ini menjalankan prototype rancangan sistem informasi mahasiswa dengan fitur Virtual Account sebagai media pembayaran perkuliahan di Universitas Raharja.

\section{HASIL DAN PEMBAHASAN}

\subsection{ANALISA PERMASALAHAN}

Dengan perkembangan teknologi yang semakin pesat, sistem sistem baru bermunculan, yang memudahkan manusia melakukan aktivitasnya sehari-hari, seperti sistem pembayaran perkuliahan misalnya, sekarang teknologi pembayaran menggunakan Virtual Account banyak dipakai perusahaan atau instansi guna mempermudah pengguna atau pemakai jasanya untuk melakukan pembayaran serta kemudahan dalam segi pembukuan dan laporan.

Dalam kasus ini Universitas Raharja pada sistem pembayarannya masih menggunakan sistem manual dimana mahasiswa melakukan pembayaran pada kasir Raharja, danyang ingin dibuktikan pada penelitian ini adalah menganalisa keunggulan dan kelemahan dalam pemakaian sistem Virtual Account jika digunakan dalam melakukan pembayaran dalam Universitas Raharja. Dan juga dampak yang muncul dengan penggunaan sistem tersebut. Namun lingkup permasalahan penulis membatasi dengan hanya permasalahan analisa serta prototype sistem virtuual acount, dikarenakan syarat pengimplementasian pembayaran Virtual Account, Instansi terkait dalam hal ini Universitas Raharja harus bekerja sama untuk penggunaan API Bank ke dalam sistem kampus

\subsection{METODE ANALISA}

Dalam metode analisa ini penulis menggunakan Unified Modeling Language (UML) untuk menganalisa sistem pembayaran Virtual account, maka dalam penelitian ini penulis menggunakan program Visual Paradigm) untuk menjabarkan rancangan prosedur sistem yang berjalan. Dan dalam penganalisaan, penulis menjabarkan analisa SWOT, Use Case Diagram, Activity Diagram, Squences Diagram

\subsubsection{Analisis SWOT}

Tabel 1. Analisis SWOT Sistem Virtual Account

\begin{tabular}{|c|c|}
\hline Strength (S) & Weakness (W) \\
\hline $\begin{array}{l}\text { 1. Tidak perlu membawa uang cash } \\
\text { 2. Transaksi bisa dilakukan dengan mudah dan } \\
\text { dalam waktu } 24 \text { jam } \\
\text { 3. Lebih disukai karena kemudahannya } \\
\text { 4. Bisa dilakukan dimana saja } \\
\text { 5. Transparan dan efisien } \\
\text { 6. Pembukuan otomatis }\end{array}$ & $\begin{array}{l}\text { 1. Masih ada orang yang ragu dengan } \\
\text { sistem pembayaran online } \\
\text { 2. Jika terjadi kesalahan, proses pengecekan } \\
\text { akan memakan waktu } \\
\text { 3. Pembuatan sistem membutuhkan biaya } \\
\text { 4. Membutuhkan Staff Ahli untuk } \\
\text { memelihara sistem }\end{array}$ \\
\hline Opportunities (O) & Threat (T) \\
\hline $\begin{array}{l}\text { 1. Mindset masyarakat yang semakin } \\
\text { terbuka akan teknologi } \\
\text { 2. Penggunaan Smartphone pada } \\
\text { semua kegiatan keuangan dalam } \\
\text { masyarakat } \\
\text { 3. Kepopuleran E-Payment } \\
\text { 4. Masih jarang Universitas yang menggunakan }\end{array}$ & $\begin{array}{l}\text { 1. Penipuan akan informasi palsu } \\
\text { 2. Cyber-thread } \\
\text { 3. Pesaing semakin banyak }\end{array}$ \\
\hline
\end{tabular}


Berdasarkan identifikasi analisis SWOT yang dilakukan, maka selanjutnya melakukan analisa untuk mencari strategi menggunakan tabel matriks SWOT. Matriks SWOT yaitu matriks yang menggambarkan secara jelas peluang yang tersedia dengan menggunakan strategi S-O dan kekuatan untuk mengatasi sebuah ancaman dengan menggunakan strategi S-T, lalu analisis strategi yang bertujuan untuk mengurangi kelemahan yang dimiliki sistem dan untuk meraih sebuah peluang yang ada dengan menggunakan strategi W-O, mengatasi ancaman dengan menggunakan strategi W-T. Berikut ini merupakan tabel Matriks SWOT:

Tabel 2. Matriks SWOT Yang Diusulkan

\begin{tabular}{|c|c|c|}
\hline Internal & $\begin{array}{l}\text { Strength (S) } \\
\text { Kekuatan }\end{array}$ & $\begin{array}{c}\text { Weakness }(W) \\
\text { Kelemahan }\end{array}$ \\
\hline & SO & Wo \\
\hline $\begin{array}{c}\text { Opportunities }(O) \\
\text { Peluang }\end{array}$ & $\begin{array}{l}\text { Dengan diterapkan sistem E-Payment, } \\
\text { akan menarik para calon mahasiswa baru } \\
\text { untuk mendaftar di Unicersitas Raharja } \\
\text { dikarenakan kemudahan akan pembayaran } \\
\text { Perkuliahan yang bisa dilakukan dimana } \\
\text { saja dan kapan saja }\end{array}$ & $\begin{array}{l}\text { Menambahkan Staff ahli untuk } \\
\text { meningkan mutu dan pelayanan, } \\
\text { dan bekerja sama dengan pihak } \\
\text { Bank dengan menggunakan API }\end{array}$ \\
\hline & ST & WT \\
\hline $\begin{array}{l}\text { Threats }(T) \\
\text { Ancaman }\end{array}$ & $\begin{array}{l}\text { Membuat Tampilan sistem se sederhana } \\
\text { mungkin agar dapat dipahami oleh } \\
\text { mahasiswa dan membuat tampilan alurnya } \\
\text { Dan Membuat security sistem berlapis } \\
\text { untuk menjamin keamanan }\end{array}$ & $\begin{array}{l}\text { Membuat help center untuk mengedukasi } \\
\text { mahasiswa agar menjalankan prosedur } \\
\text { dengan benar guna menghindari kesalahar }\end{array}$ \\
\hline
\end{tabular}

\subsubsection{Use Case Diagram yang Dirancang}

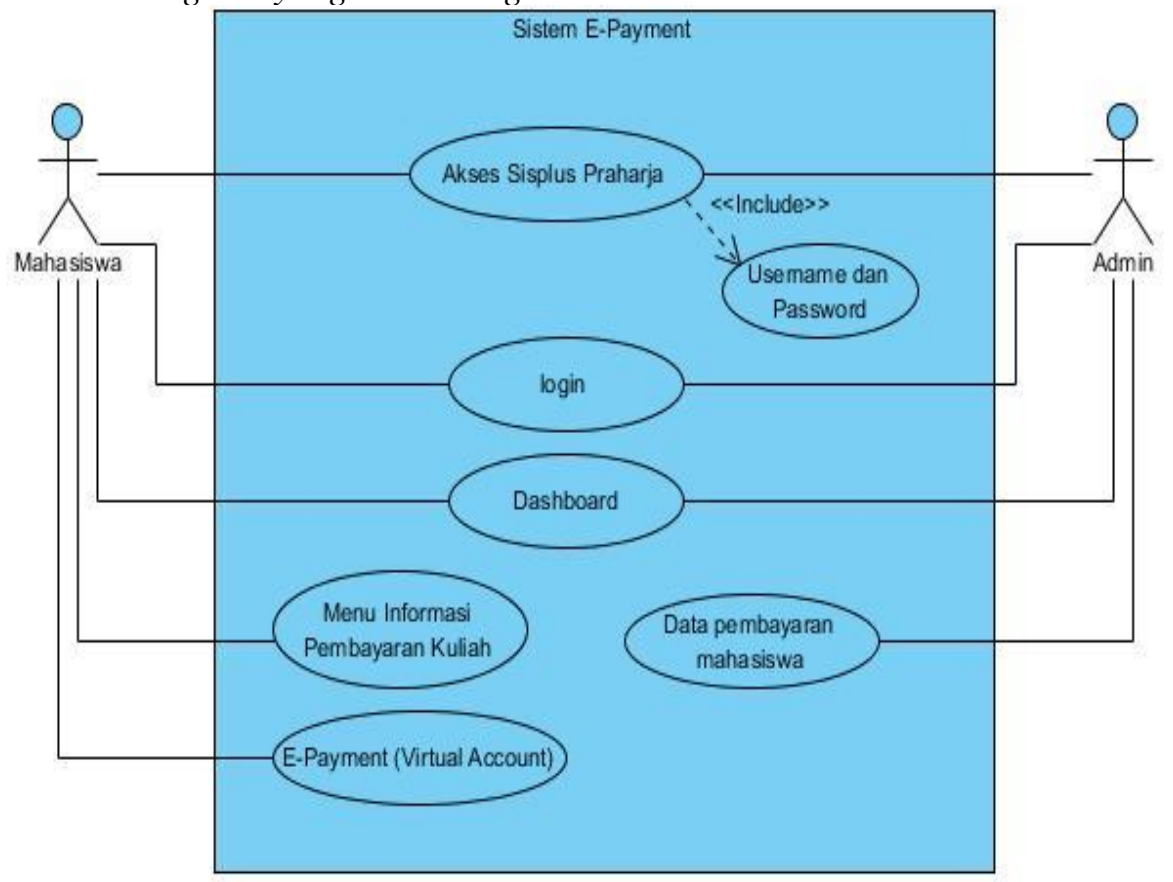

Gambar 2. Use Case Diagram 
Dapat dijelaskan gambar di atas merupakan use case diagram yang diusulkan, yaitu terdiri dari:

1. $\quad 2$ (dua) Aktor yang melakukan kegiatan yaitu: Mahasiswa dan Admin.

2. 1 (satu) Sistem yang mencakup seluruh kegiatan

3. 6 (enam) Use Case yang Mengakses Sistem pembayaran Kuliah: Akses Sisplus, login, dashboard, menu informasi pembayaran kuliah, E-payment (Virtuall Account), Data pembayaran mahasiswa

\subsubsection{Activity Diagram Yang Dirancang}

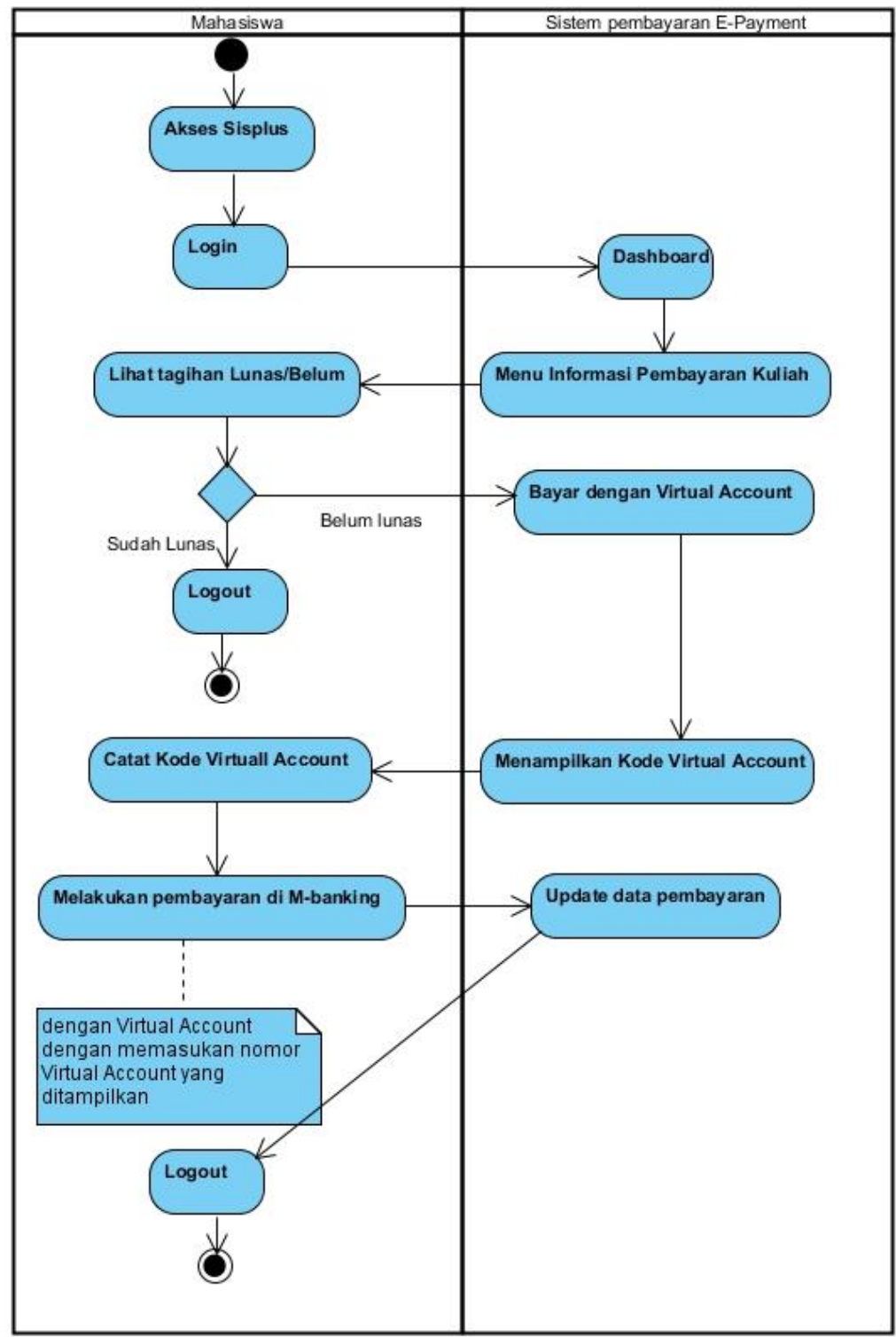

Gambar 3. Activity Diagram Mahasiswa

Dapat dijelaskan dari gambar 3 yang merupakan gambar activity diagram untuk Mahasiswa, yang mana terdapat:

1. 1 (satu) initial node sebagai objek yang di awali.

2. 11 (sebelas) activity sebagai state dari sistem yang mencerminkan eksekusi dari suatu aksi diantaranya, yaitu : Akses Sistem informasi kampus, Login, Dashboard, Menu 
informasi pembayaran kuliah, menu pembayaran virtual account, lihat tagihan, menampilkan kode nomor virtual account,catat kode, melakukan pembayaran via $\mathrm{M}$ Banking, Teller, ATM, Update data pembayaran, logout.

3. 1 (satu) initial final node yang merupakan aktifitas akhir kegiatan.

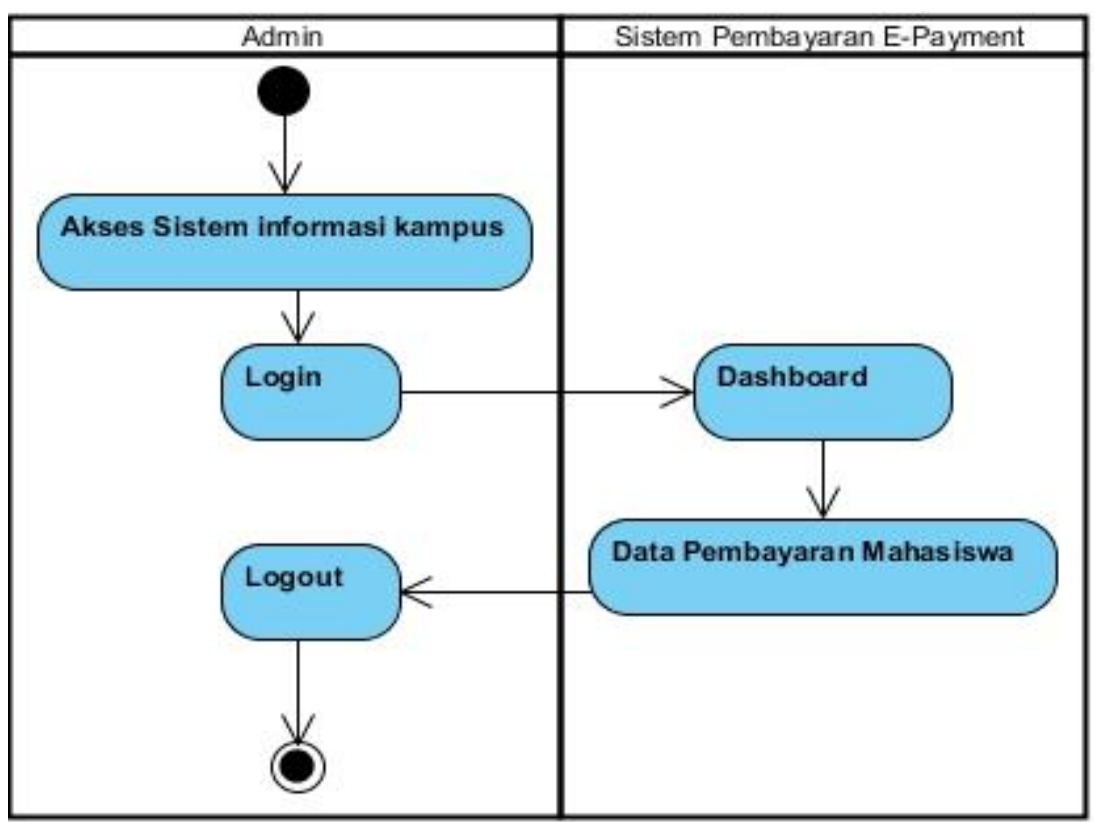

Gambar 4. Activity Diagram Admin

Juga dari gambar 4 di atas yang merupakan gambar activity diagram untuk Admin, yang mana terdapat:

1. 1 (satu) initial node sebagai objek yang di awali.

2. 5 (lima) activity sebagai state dari sistem yang mencerminkan eksekusi dari suatu aksi diantaranya, yaitu :Akses Sistem informasi kampus, Login, Dashboard, Data pembayaran mahasiswa, logout.

3. 1 (satu) initial final node yang merupakan aktifitas akhir kegiatan.

\subsubsection{Sequence Diagram Yang Dirancang}

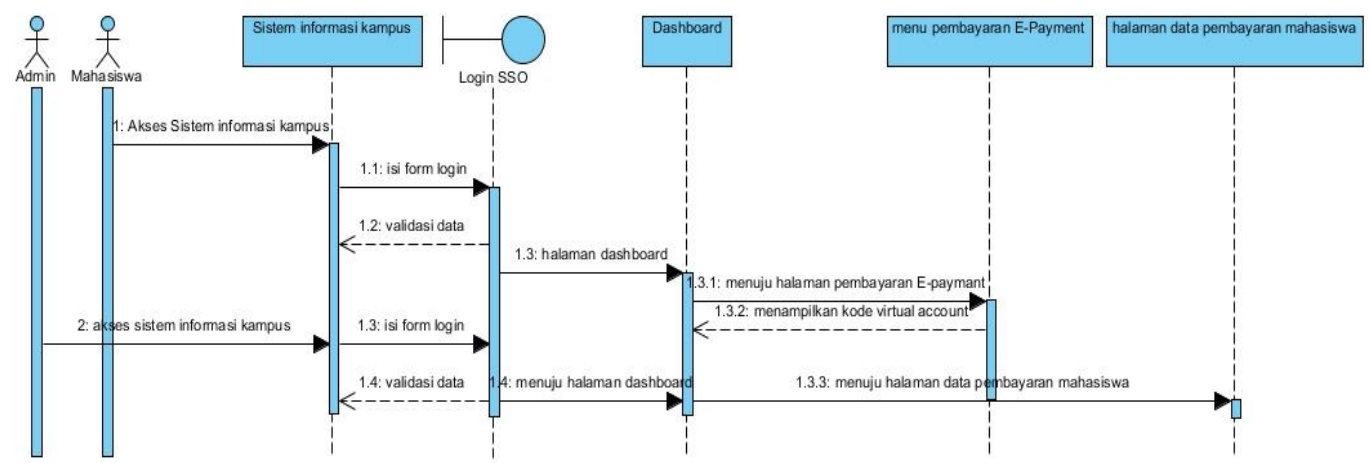

Gambar 5. Sequence Diagram

Gambar 5. Sequence Diagram yang diusulkan diatas menggambarkan sequence diagram yang berjalan, yaitu sebagai berikut:

1. $\quad 2$ (dua) aktor yang melakukan kegiatan, yaitu Mahasiswa dan Admin. 
2. 2 (dua) entity class untuk menggambarkan sebuah penggambaran Sistem informasi kampus,Dashboard, menuTagihan, halaman data pembayaran mahasiswa

3. 1 (satu) boundary class untuk menggambarkan sebuah penggambaran dari loginSistem informasi kampus.

4. 7 (tujuh) Message yang menggambarkan pengiriman pesan, yaitu:
a. Akses Sistem informasi kampus untuk Mahasiswa.
b. Login menggunakan email kampus untuk mahasiswa.
c. Halaman dashboard.
d. Menuju haman E-Payment Virtual Account
e. Akses Sistem informasi kampus untuk Admin
f. Login menggunakan email kampus untuk Admin
g. Menuju halaman data pembayaran mahasiswa

\subsection{IMPLEMENTASI}

Perancangan sistem View Virtual Account pada halaman Tagihan mahasiswa dimana dalam haman menampilkan jumlah matkul yang di ambil dan total biaya yang harus dibayar serta label status tagihan dan juga button untuk menampilkan kode virtual account mahasiswa

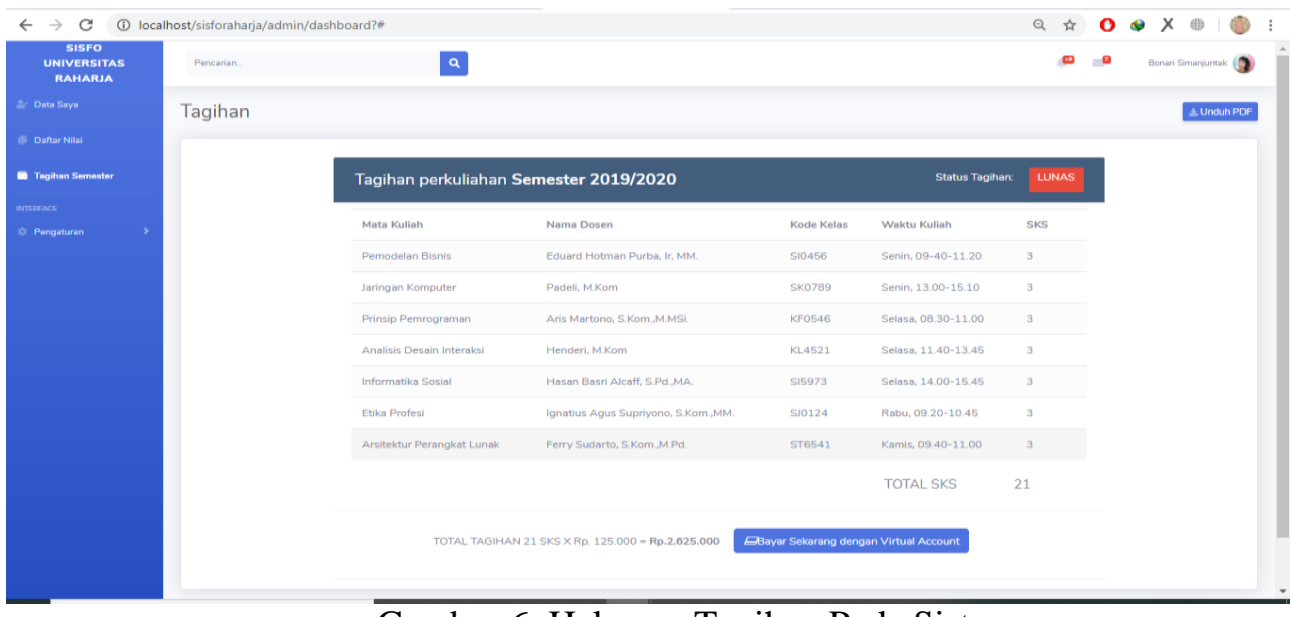

Gambar 6. Halaman Tagihan Pada Sistem

Dalam sistem informasi mahasiswa Universitas Raharja dibuat halaman tagihan mahasiswa seperti tampilan pada Gambar 6. Yang menampilkan tagihan semester para mahasiswa dalam tabel dan ada label status tagihan di pojok tabel jugadibuat tombol pembayaran dengan virtual account.

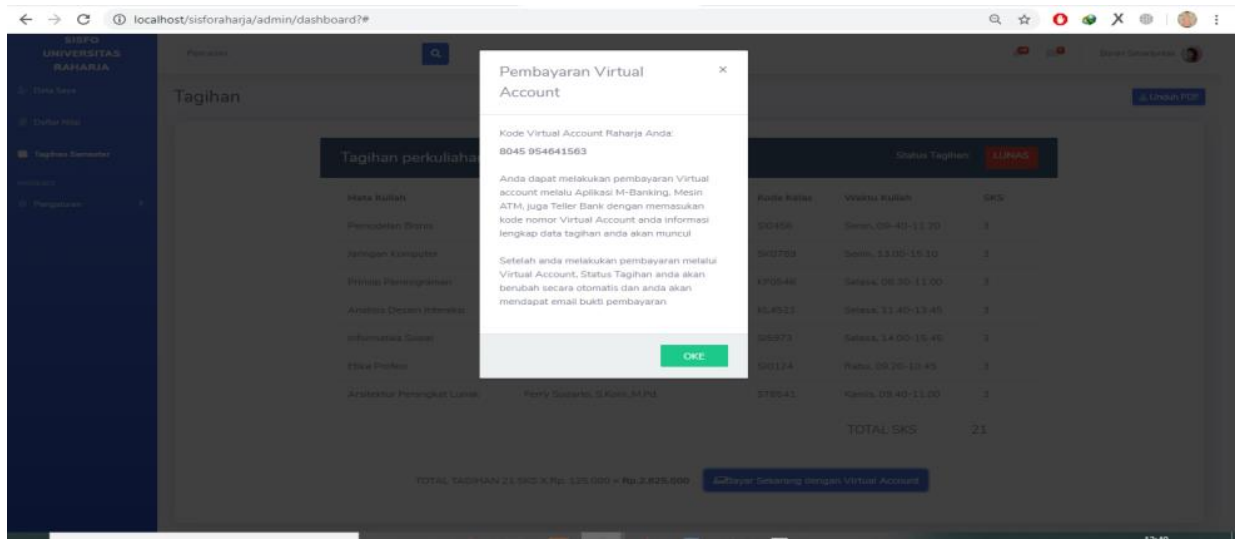

Gambar 7. Menampilkan Nomor Virtual Account mahasiswa 
Pada Gambar 7. Menampilkan Nomor Virtual Acoount mahasiswa saat button pembayaran virtua account di klik. Nomor virtual acoount unutk kode pembayaran yang dilakukan mahasiswa pada bank untuk pembayaran perkuliahan

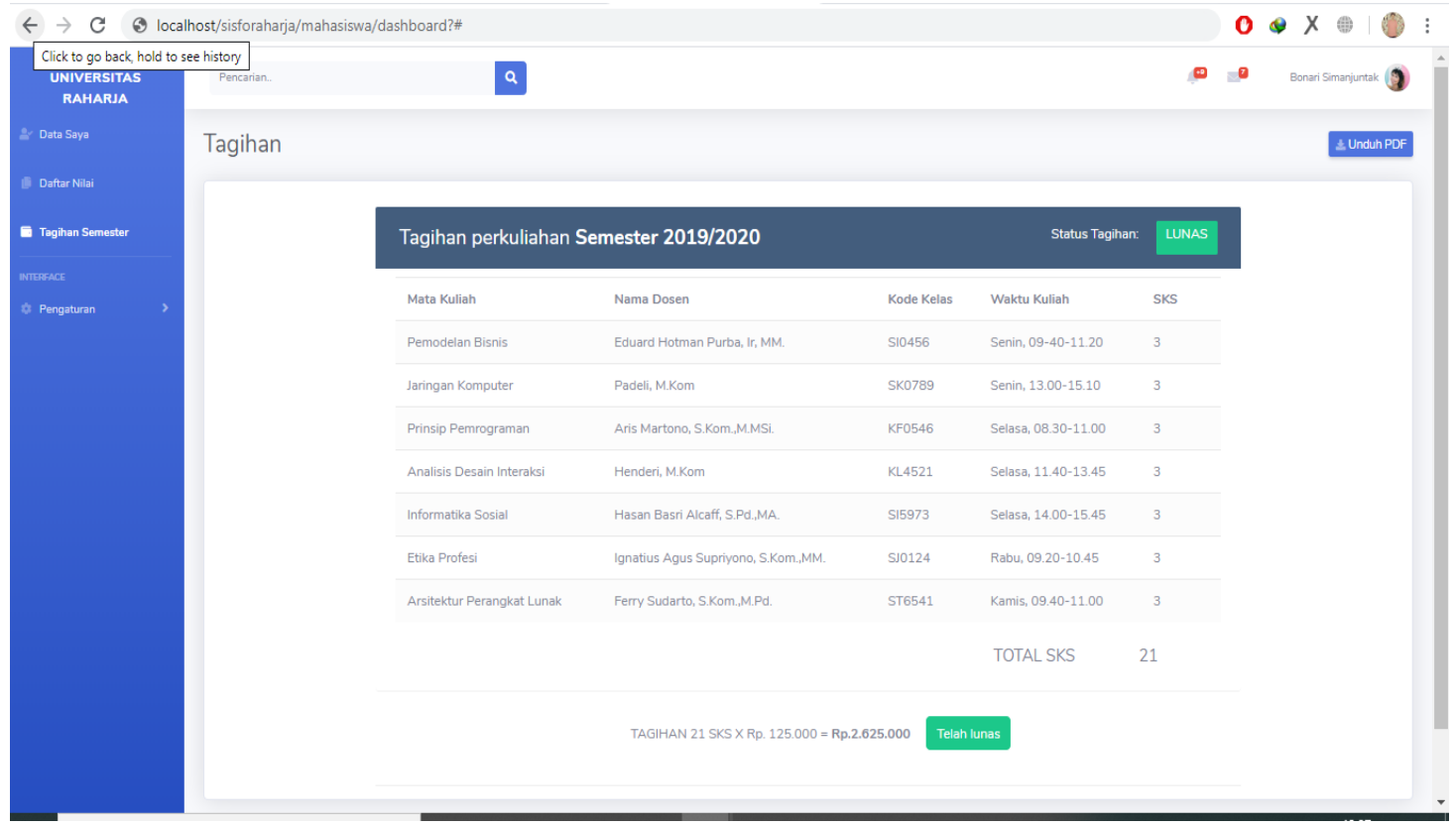

Gambar 8. Sinkronisasi Pembayaran By Sistem

Pada Gambar 8. Adalah terupdatenya data secara Real-time pada saat mahasiswa berhasil melakukan pembayaran dengan virtual account yang akan berubah menjadi lunas

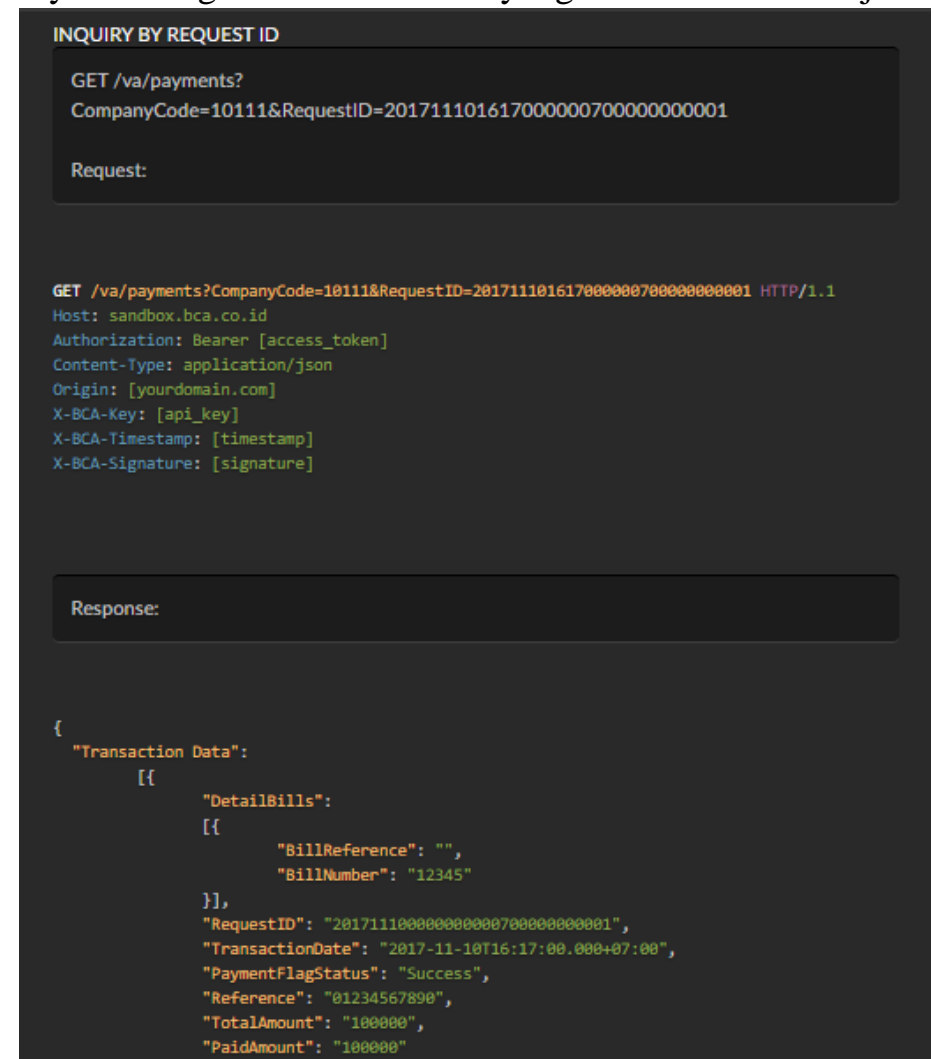

Gambar 9. API BCA untuk fitur Virtual Account 
Dalam Gambar 9. sistem dimana penerapan API dibuat seperti code di atas.

\section{KESIMPULAN}

Setelah melakukan analisisa terhadap system pembayaran perkuliahan dengan sistem virtual account, penulis mencoba mengambil kesimpulan dan memberikan saran sebagai berikut

1. Dari analisa yang sudah dipaparkan sistem Virtual Acount untuk pembayaran perkuliahan kampus akan meningkatkan efektivitas dari pemanfaatan web/internet guna kemudahan dalam pembayaran perkuliahan,selain itu kemajuan teknologi di lingkungan kampus akan semakin kuat, dan menjadi suatu keunggulan kampus dibanding kampus lain yang tidak menggunakan sistem pembayaran Virtual Account.

2. Fokus pada aspek teknologi yang memang pada tujuan utama universitas raharja memajukan ilmu teknologi informasi para mahasiswanya dengan cara meninggalkan sistem lama dan terbuka pada perkembangan teknologi sekarang ini, dalam hal ini sistem pembayaran Virtual Account

3. Penulis berharap agar sistem dapat dijadikan analisa dan rancangan ini dapat di jadikan model untuk penelitian dan pengembangan lebih lanjut

4. Namun dalam penerapan sistem Virtual Account, pihak universitas harus bekerja sama dengan pihak bank agar dapat menerapkan fitur (menjalankan API dari bank pada sistem kampus) ini dalam sistem informasi kampus Raharja

Analisa dan rancangan sistem virtual account ini tentunya dapat menjadi solusi untuk masalah agar pembayaran perkuliahan di Universitas Raharja dapat lebih efisien dan efektif bagi mahasiswa dan juga bagi kampus. Dari rancangan ini penulis berharap agar proyek rancangan ini dapat di terapkan di Universitas raharja. Dengan kemudahan dan efisiensi dalam proses pendaftaran akan meningkatkan image kampus sekaligus mendongkrak citra kampus yang relevan dengan teknologi dewasa ini

Dari hasil perancangan sistem pembayaran virtual account ini semoga dapat dijadikan bahan pemikiran untuk program serupa dan dikembangkan lebih sempurna

\section{SARAN}

Saran yang dapat disampaikan oleh penulis adalah agar penelitian berikutnya dapat mengembangkan sistem pembayaran pendaftaran mahasiswa baru menjadi lebih baik lagi. Saran yang digunakan sebagai bahan pertimbangannya, terdiri dari 3 (tiga) diantaranya:

1. Pengelolaan sistem pembayaran harus disempurnakan melalui konsep dan strategi pengembangan yang baru, sehingga lebih menarik dibandingkan instansi pendidikan yang lain

2. Diharapkan dapat dijadikan bahan masukan untuk instansi terkait dalam meningkatkan mutu pelayanan pembayaran perkuliahan di Universitas Raharja.

3. Diharapkan setiap anggotanya lebih aktif dalam memberikan saran dan masukan agar sistem selalu terpantau

\section{DAFTAR PUSTAKA}

[1] Untung Rahardja, Qurotul Aini, Made Bunga Thalia (2017). Penerapan menu konfirmasi pembayaran online, Citec Journal, Vol 4, No 3.

[2] Zlatko Bezhovski (2016). The Future of the Mobile Payment as Electronic Payment System. European Journal of Business and Management, ISSN 22221905 (pp.127-132). 
[3] Erikson Damanik (2012). Perancangan sistem informasi pembayaran online menggunakan Payment Gateway. Jurnal SIFO Mikroskil Vol. 13, No. , ISSN. 1412-0100

[4] Dwiki Fahliandini (2016). Penerapan Nomor Virtual Account sebagai media pembayaran perkuliahan pada perguruan tingggi. Tugas Akhir, Jurusan Sistem Informasi, AMIK Raharja, Tangerang.

[5] Mohammad Auwal Kabil, Siti Zabaedah Zaidin and Aidi Ahmi (2015).At International Conference on E-Commerce (ICoEC) 2015, 20-22 Oktober 2015, Kuching, Sarawak, MALAYSIA.

[6] Ajeet Singh, Karan Singh, Sahazad, M.H Khan, (2012). A Review: Secure Payment System for Electronic Transaction. International Journal of Advanced Research in Computer Science and Software Engineering, Vol 2, Issue 3, ISSN:2277 128x.

[7] Stephen Kwadwo Antwi,Kasim Hamzah, Shadrach Wusah Bavoh (2015) SElectronic Examining the Effectiveness of Electronic Payment System in Ghana: The Case of e-ZWICH in the Tamale Metropolis.Research Journal of Finance and Accounting ISSN 2222-1697 (Paper) ISSN 2222-2847 (Online) Vol.6, No.2, 2015

[8] Saviour F. (2017). A Study on Popularity of Various Utilities of E-Payment Mechanism among Students. International Journal of Science and Research (IJSR), ISSN :2319-7064. 